\title{
Suggestive techniques connected to medical interventions
}

\author{
KATALIN VARGA \\ Department of Affective Psychology, Institute of Psychology, Eötvös Loránd University, Budapest, Hungary \\ Corresponding address: Katalin Varga; Izabella u. 46, H-1064 Budapest, Hungary; E-mail: varga.katalin@ppk.elte.hu
}

(Received: March 28, 2013; Revised manuscript received: July 17, 2013; Accepted: July 23, 2013)

\begin{abstract}
The paper introduces a series of articles where several detailed clinical examples will be presented on the effectiveness of using suggestive techniques in various fields of interventional medicine. The aim of this series is to raise the attention to the patients heightened openness to suggestions. By recognizing the unavoidable nature of suggestive effects on one hand we can eliminate unfavourable, negative suggestions and on the other hand go on and consciously apply positive, helpful variations. Research materials, reviews and case study will describe the way suggestions can reduce anxiety and stress connected to medical intervention, improve subjective well-being and cooperation, and increase efficiency by reducing treatment costs.
\end{abstract}

Keywords: medical communication, hypnosis, suggestive techniques, critically ill, trance state

\section{Introduction}

Communication is one of the key points of medicine, especially when complicated, painful or difficult medical interventions are needed. The intervention that is simple and routine for the health professional (HP) may well be considered as something incomprehensive and threatening for the patient $[1,2]$.

"More problems and difficulties arise from poor communication than from anything else in all medical and nursing practice [3]." Bad communication leads to mistrust and disrespect, and reduces the effectiveness of the technological, financial and human investment.

There are several examples, however, that very simple communicational elements can make the medical intervention much more effective. For instance, in a classical study usual care patients were compared with the "suggestion" group, when trained ambulance attendants told the injured patient the following:

The worst is over. We are taking you to the hospital. Everything is being made ready. Let your body concentrate on repairing itself and feeling secure. ... Things are being made ready at the hospital for you. We're getting there as quickly and safely as possible. You are now in a safe position. The worst is over [4].
This half-minute intervention resulted in an increased survival rate during transport to the hospital, shorter hospital stay and faster recovery in the members of the suggestion group.

Several further examples could be mentioned highlighting the importance of the topic:

- E.g. Evans and Richardson's report [5] on the possibility to save $£ 12$ million a year in England (at 1989 prices) by reduced drug requirement and hospital stay solely by a 12-minute suggestive message from a tape during an operation to anaesthetised(!) patients.

- Or Cheek's findings [6] that if we speak to a comatose or sedated patient, the chance of survival is increased.

- Or Gruzelier et al.'s research [7] that by describing the proper function of the immune system the beneficial effect is reflected not only in the immune measures, but people showed a lower rate of contracting the infection, and a greater speed of recovery, than those in a control group (who did not get the messages).

It has been clear for hundreds of years: words have power. It is time to supplement somatic-based medicine with this approach. In this series of papers of 
the journal we will summarize our results on the use of suggestive techniques in various medical settings.

In this introductory paper the concept of suggestive communication will be defined, the reasons why HPs should take into consideration the heightened suggestibility of patients is explained. I will briefly describe the structure and the main characteristics of the Psychological Support Based on Positive Suggestions (PSBPS) training we use to teach HPs for this approach, and some special applications will be highlighted.

\section{Ancient techniques in modern medicine}

The use of suggestive techniques has been documented for over 5000 years [8]: the healing centre in the Egyptian city of Saqqara, the sleep temples of Greece, the shamanistic rituals in various cultures of the word all have suggestive or hypnotic elements. There are some memorable moments during these five thousand years that have direct relevance from a modern medical point of view:

- In 1829 Jules Cloquet performed the first surgery with hypnoanesthesia on a breast cancer patient. Some years later James Esdail performed 261 painless operations with mesmeristic techniques, including removal of big tumours or amputations. The mortality of his practice was only $5 \%$ (compared to the $50 \%$ of that time) but none of the fatal cases were directly connected to surgery. No wonder that soon a whole hospital had been opened based on this technique in Calcutta.

- In 1857 a French pharmacist, Emile Coué noticed the strong effects of placebos and positive suggestions. Coué's observation was that if the medication is given with positive suggestions patients heal faster.

- One of the recent examples of use of suggestive techniques in healing is that of Milton H. Erickson, who used self-hypnosis to overcome the pain and stiffness caused by his polio.

During its long history, hypnosis and suggestive methods many times suffered very bad reputations for various reasons: professionals found it mystical, the church did not accept it and the general public did not trust the method. Unfortunately due to this unfavourable atmosphere even those who applied the suggestive techniques successfully oftentimes kept their results unpublished.

Nowadays we see the renaissance of application of suggestive techniques in modern biomedicine. This return can perhaps be attributed to the reputation hypnosis gained in scientific research. Modern studies looking for the neuropsychological correlates of hypnosis have demonstrated the brain correlates of hypnotic suggestions (for summary, see [9-13]).

\section{Suggestive communication vs. hypnosis}

Suggestions are verbal or nonverbal messages that the receiver involuntarily accepts and follows. Not only our spoken or written words but the environment, objects and nonverbal messages (eye contact, sighs, and touches) can have suggestive effects. The person in a special (altered) mental state - like most of the patients of medical interventions - can be highly susceptible to suggestions, sometimes may follow them literally (so-called literalism).

All the elements of medical communications - e.g. introducing our clinic on the website, decorating our waiting room, reporting the diagnosis, explaining the planned intervention, telling the prognosis or death of a relative, just to mention a few - may have a suggestive effect even if we know nothing about the suggestive method. This is good from the perspective of deliberately applied positive suggestions, but makes patients defenceless against unfavourable ones.

In case of formal hypnosis special techniques (called induction methods) are used to make the subject more susceptible to suggestions. But we can use suggestive method without inducing hypnosis, simply based on the special trance state we can suppose in the patient. This circumstance makes it possible for those colleagues who have no right by law to use formal hypnosis in health care situations to nevertheless apply the elements of suggestive communication in their daily work. Many experts of the field state that the patient of medical interventions can be considered to be highly open to suggestions, as if already hypnotized, even without any formal hypnotic induction [see e.g., 1, 2, 6]. In Hungary, for instance only medical doctors, dentists and psychologists are allowed to use hypnosis for healing purposes. As we will see below, other HPs can use "suggestive techniques" without inducing hypnosis itself.

\section{Special trance state and increased suggestibility}

During medical interventions patients usually find themselves either in a reduced or an extremely complex, incomprehensible environment. There are many factors that create an altered state of consciousness (also called trance state): patients do not know the various monitors and technical equipment around them, they are lying motionless for hours (or days, even weeks), usually do not understand the intervention, etc. Consequently most of them simply accept everything, without critical judgment. 
The trance state in medical settings, however, is not usually a pleasurable one. The negative trance state of patient fulfils the criteria of "critically ill" patients, from a psychological point of view as well $[1,14]$.

Just like people in general, patients also react to suggestions to different extents and have different levels of suggestibility. This "original" level, however, increases when one faces a medical intervention: patients are open to anything that gives an idea of what they can expect, what they have to do. Most of the patients are in a state of "hunger for signs", becoming open to every "message" - unfortunately also to the harmful ones. What a patient feels in an incomprehensible medical intervention in an unknown environment, can be compared to entering a completely dark room in an unknown building and trying to work out which way to go. Every directing gesture, sign or movement has a heightened effect in this situation.

Patients become very susceptible to the signs which can help them interpret the uncontrollable situation in which they find themselves. These messages can especially be effective if they come from an authority figure (surgeon, physician). Due to the trance state patients may accept the idea or content of the suggestion as their subjective reality. They became emotionally convinced that the world is really just as the suggestions describe it.

Medical patients, due to their trance state tend to execute or follow suggestions automatically, without logical analysis or critical evaluation. The usual characteristics of trance state are relevant here: overshadowed reality testing, alterations of meaning, space- and timesense and body image.

That is why it is so important to realize that patients are as susceptible to suggestions in the period around disease/injury as if they were being hypnotized; and the rules about the application of hypnotic suggestions can be directly transferred to everyday medical practice.

During medical treatment the increased suggestibility frequently meets (unintended) negative suggestions coming from the professionals or from the physical environment, as HPs are usually not aware of the heightened openness to suggestions:

- "Tell me when you have pain" - suggests that pain is unavoidable.

- "At the end of the operation we usually wake up our patients" - clearly can be interpreted unfavourably, though the original intention was to inform the patient that she might find herself in an ICU for postoperative observation.

- Putting the poster of a cancer patient surgery (illustrated with photos) on the wall of a waiting room of an otolaryngology department is not the best idea to keep the next patient calm...

All these are real examples from various medical settings.

\section{Various ways of cognitive processing}

While analysing unfavourable communications, we many times find that HPs did not tailor their messages to be responsive to the special mental state of the patient. When we are working with patients, we must be aware of the fact that our partner can be in an altered mode of processing communicative messages. That is why sometimes there might be a sharp contrast between our intention and the way the patient perceives our message.

Basically we can take into consideration the continuum of ways of functioning with the "dominant" mode at the one end and the "alternative" on the other end, with many shadows in between these two extremes [15].

The dominant mode is the logical, rational, critical, analysing/planning mode, while the alternative is the holistic, metaphorical and intuitive mode of cognitive operation. Patients often shift from the "dominant" end of the cognitive spectrum towards the "alternative" processing that can completely change the meaning of the message that seemed to be all right in the "dominant" mode. For example the statement "that is it" referring to the end of the intervention may be interpreted by the patient that this is the end of his life [16].

Or: when the assistants says: "We have a problem here, I should ask the doctor" the patient will interpret it that the problem is related to her illness, not to the equipment (which was the actual case) [17].

Adjusting our messages to the patient's current most probably "alternative" - mental mode of cognitive operation, we can increase the effectiveness of communication. Many times a patient will be much more strongly affected by a well-chosen metaphor or suggestion than by logical (medical) arguments.

Preparing someone for a surgery, for instance, in the "dominant" mode of working consists of precisely worked-out steps (planning), breaking down the complex processes (detailing), constantly measuring the laboratory results (evaluation), and diligently checking the outcome measures as well. The same goal can be pursued in the alternative mode, for example, by setting the objective (goal) that the patient will be able to spend summer holiday with the family following the operation (objective orientation); getting her to imagine this scene vividly (visual processing); perhaps introducing someone who has already succeeded in the same type of operation (following a positive model); and asking the person what she feels, about how the objective will be realised in a positive way (intuition), and so on.

Health professionals usually communicate using the principles of the dominant mode - perhaps due to the style and knowledge learned during their training. This has a very good effect on some situations: many patients require instructions or information based on logical, rational explanations. Others - or the same patient on another day - however, prefer an alternative mode of com- 
munication. So in most cases, both the rational sphere and the alternative mode of operation can be applied. Now, very good books are available to learn the rules to be followed in composing suggestions, based on alternative modes of operation [see e.g., 18-20].

\section{The nature of suggestions}

To give an impression of suggestive messages in medical practice, let us take the example of the intensive care unit (ICU). Here the environment is usually strange and frightening to patients due to the seemingly chaotic and tangled cables and tubes and bleeping monitors, and hissing ventilators. We can reframe the machines instead of sources of awesome noise describing them as the sources of security [following the principles of 1,2 ].

The machines around you continuously monitor the needs of your body. The beeps are signals for us, just serving your safety. As you see, there is always someone observing the machines, and doing what is needed when it is needed [19].

Sometimes we can even go on creating a positive, comfortable scene and not simply neutralizing the possibly uncomfortable environment, as:

And since you are safe, and the nurses and doctors are taking care of you, you can feel safe and relaxed, and leave the machines and the nurses and doctors to keep a close watch over you. Consider this, and you will find these sounds much more reassuring. Some imagine that these noises are that of a pleasant boat-ride, a cruise, this way their attention can be focused on the comfortable aspects of this trip... these sounds serving as background noise to this pleasant scene [19].

It is important to realize that these messages are true reinterpretations of the environment; there is no misleading or cheating in it. These suggestions can well be applied even to a comatose or sedated patient.

Most of the papers in the series of articles on suggestion in the journal will provide further examples of applied suggestions.

\section{Handling difficult medical situations and further possibilities}

The suggestive communication strategies proved to be very effective in various medical interventions. Various situations with the "difficult patient" could be solved based on the suggestive technique - e.g., refusal of treatment, extreme pain, bad communication of colleagues, suicidal patients, extreme anxiety, panic attack (during
Caesarean section), interventions with mentally handicapped patients, in cases of grief, losses, and even at street accidents. Examples:

- A postoperative surgical patient who was extremely agitated, confused and aggressive (believing that his money had been stolen) could be calmed down by rationally explaining the reality (dominant mode), but the communication was based on the rules of suggestive techniques.

- Another patient with suspect deep vein thrombosis refused further diagnostic intervention and treatment. In his case the logical explanation did not work, but a well-chosen metaphor persuaded him.

- A patient with a complex bone fracture - whose wound started to bleed severely the $1^{\text {st }}$ postoperative day at the Intensive Care Unit - could be calmed down to accept the necessary intervention by using suggestive method based on physical touch and breathing together(!) with the doctor of the ICU.

- The MRI examination of a 7-year-old mentally retarded patient could be solved without anaesthesia: he could stay motionless and cooperative immersed in a positive imagination offered by the assistant.

Detailed case studies are also available for readers to follow step by step instructions on suggestive techniques applied in various cases [see e.g., 17, 21, 22]. Even the way two different health professionals approach two patients, both suffering from Guillain-Barré syndrome, can be compared, followed by the common elements and the way the approach can be tailored to the unique needs of the given patient $[23,24]$.

\section{Psychological Support Based on Positive Suggestions (PSBPS) training}

In Hungary there are very good trainings to learn the rules of suggestive communication. Medical doctors, dentists and psychologists can become hypnotherapists, and implement hypnosis (or hypnotic techniques) into their daily practice (see the possibilities at www.hipnozismhe.hu).

For other health professionals a special training has been developed, as they are not allowed in our country to use formal hypnosis in health care. The training is called "Psychological Support Based on Positive Suggestions (PSBPS)", and jointly accredited by the Department of Anaesthesiology and Intensive Therapy of Semmelweis University, Budapest, Hungary, and the Hungarian Association of Hypnosis.

The main elements of the training are the followings: The training is run in small groups including trainees ("students") from various professions: doctors, nurses, psychologists, physiotherapists, midwives, assistants, and 
so on. It is useful to have such "mixed" groups, as they can share their viewpoints and serve as "outsider" points of reference for each other. A psychologist e.g., can explain to a dentist what the most fearful elements of a dental treatment can be, or a doctor - who is actually pregnant with the first baby - can have "real" questions to a midwife. These discussions can be considered as models of everyday doctor-patient communications. The small (max. 20 participants) group and friendly situation make it possible to create an appropriate atmosphere for sharing professional and personal experiences.

The teachers of the training are also coming from various fields and professionals, just like the students: doctors, nurses, psychologists, physiotherapists, midwives. Participants are encouraged to "learn" from other fields as most of the suggestive techniques and approaches can easily be applied in any field of medicine (pain control, bleeding control, anxiety reduction, better cooperation, etc.).

The time frame of the training is deliberately extended: there are altogether 70 teaching hours, divided into 14 teaching days, so that the whole training lasts 5 months. The personal meetings are scheduled 2-3 weeks apart(!), so the participants can embed the acquired material into their daily practice in their field. For the next meeting they bring their experiences, successes and possible difficulties, which are subject to group discussion. The extended timing of the training days is due to our experience that trained professionals use these suggestive techniques automatically only after a while, where no conscious effort is needed to create appropriate suggestions. There is a period where the "old" communicational panels are not working, but the trainee is not yet skilled enough in the new techniques. It proved to be useful to wait to the time of appropriate fluency. Just like when acquiring a foreign language; at a certain level the initial difficulties with certain structures disappear, and the rest comes naturally.

The training is based on lectures, demonstrations, video-analyses, case-analyses, situational exercises, homework and so on. The training ends with an exam that has a written and an oral part, in front of a committee. The ex-students of the training are free to attend 2 meetings/year, where there are 2 professional lectures and a good possibility for personal encounters.

Based on our more than 11 years of experience, the approach has proven to be useful in many areas of medicine [19].

\section{Closing remarks}

There are many positive sides of proper communication with patients. Suggestions tailored to the mental state of the individual improves their cooperation, helps avoid complications, shortens hospital stays and improves the overall long-term outcome.
It can easily be learned and embedded into daily practice. The PSBPS training proves that practically any HP can learn and follow the principles of suggestive techniques easily, this way acquiring a very effective kind of communication.

There is no extra time needed: the usual argument that "there is no time for such things" in everyday practice is simply wrong. The suggestive techniques do not require extra time or preparation during medical interventions. Just the opposite: when we have just a few minutes e.g., in an emergency situation, or in a busy office - we should apply effective methods [1, 2, 25].

One of the further benefits is that this approach costs hardly anything, but the outcome can drastically increase the cost-effectiveness of medical interventions [26].

It is my hope that this series of articles convinces the practitioners and leaders of various fields that great care is needed when communicating with patients of medical interventions.

The better results can be achieved the more health professionals - doctors, nurses, physiotherapists, psychologists, and so on - dealing with the patient will follow the individualized way of giving positive suggestions to patients of medical interventions.

\section{References}

1. Bejenke CJ (1996): Painful medical procedures. In: Hypnosis and suggestion in the treatment of pain, ed Barber JNY, W.W. Norton and Company, London, pp. 209-265

2. Bejenke CJ (1996): Preparation of patients for stressful medical interventions. Some very simple approaches. In: Munich lectures on hypnosis and psychotherapy, eds Peter B et al., M.E.G. Stiftung, Munich, pp. 27-36

3. Hjörleifsdóttir E, Carter DE: Communicating with terminally ill cancer patients and their families. Nurse Educ Today 20, 646-653 (2000)

4. Jacobs DT (1991): Patient communication for first responders and EMS personnel. Prentice-Hall, New Jersey

5. Evans C, Richardson PH: Improved recovery and reduced postoperative stay after therapeutic suggestions during general anaesthesia. Lancet 2, 491-493 (1988)

6. Cheek DB: Communication with the critically ill. Am J Clin Hypn $12,75-85(1969)$

7. Gruzelier J, Levy J, Williams J, Henderson D: Self-hypnosis and exam stress: Comparing immune and relaxation-related imagery for influences on immunity, health and mood. Contemp Hypn 18, 73-86 (2006)

8. Gauld A (1992): A history of hypnotism. Cambridge University Press, Cambridge

9. Barabasz AF, Barabasz M (2008): Hypnosis and the brain. In: The Oxford handbook of hypnosis, eds Nash MR, Barnier AJ, Oxford University Press, Oxford, New York, pp. 337-363

10. De Benedittis G: The hypnotic brain: Linking neuroscience to psychotherapy contemp. Hyp and Integrative Therapy 29, 103-115 (2012)

11. Kihlstrom JF: Neuro-hypnotism: Prospects for hypnosis and neuroscience. Cortex, 49, 365-374 (2012)

12. Kihlstrom J (2008): The domain of hypnosis revisited. In: The Oxford handbook of hypnosis, eds Nash MR, Barnier AJ, Oxford University Press, Oxford, New York, pp. 21-41 
13. Oakley DA (2008): Hypnosis, trance and suggestion: Evidence from neuroimaging. In: The Oxford handbook of hypnosis, eds Nash MR, Barnier AJ, Oxford University Press, Oxford, New York, pp. 365-392

14. Cheek DB: Hypnosis; an additional tool in human reorientation to stress. Northwest Med 57, 177-182 (1958)

15. Unestahl LE (1981): Inner mental training. Veje publishing, Örebro, Sweden

16. Ewin DM (2011): The laws of hypnotic suggestion. In: Beyond the words. Communication and suggestion in medical practice, ed Varga K, Nova Sciences, New York, pp. 75-82

17. Bányai EI (2011): Unintended suggestions, social "messages" from the perspective of an expert cancer-patient: A personal account. In: Beyond the words. Communication and suggestion in medical practice, ed Varga K, Nova Sciences, New York, pp. 337-350

18. Hammond DC (1990): Handbook of hypnotic suggestions and metaphors. W.W. Norton and Company, New York

19. Varga K (2011): Beyond the words. Communication and suggestion in medical practice. Nova Sciences, New York

20. Weitzenhoffer AM (1989): The practice of hypnotism. Wiley, New York
21. Carolusson S (2011): Brain trauma and hypnotic communication; Tobias and family love In: Beyond the words. Communication and suggestion in medical practice, ed Varga K, Nova Sciences, New York, pp. 363-380

22. Rákóczi Á (2011): Dialoges - messages around the birth of a baby. In: Beyond the words. Communication and suggestion in medical practice, ed Varga K, Nova Sciences, New York, pp. 389-400

23. Benczúr L (2011): "Bricks for the house of healing" using positive suggestions in the intensive care unit: A case example. In: Beyond the words. Communication and suggestion in medical practice, ed Varga K, Nova Sciences, New York, pp. 401-412

24. Varga K (2011): Suggestions - step by step. In: Beyond the words. Communication and suggestion in medical practice, ed Varga K, Nova Sciences, New York, pp. 413-422

25. Bejenke CJ (2011): Suggestive communication: Its wide applicability in somatic medicine. A clinician's 35 year observations, teaching and practice. In: Beyond the words. Communication and suggestion in medical practice, ed Varga K, Nova Sciences, New York, pp. 83-96

26. Lang EV, Rosen, MP: Cost analysis of adjunct hypnosis with sedation during outpatient interventional radiologic procedures. Radiology 222, 375-382 (2002) 